\title{
Availability and Utilization of Sporting Facilities for Fitness and Health Improvement of Staff of Federal College of Education, Kano, Nigeria.
}

\author{
Shuaibu Abdullahi Alhassan*, Mall. Jamilu Mohammed, Mall. Sabo Uba Yaranchi \\ Department of Physical and Health Education, Federal College of Education, Kano - Nigeria \\ *Corresponding Author: Shuaibu Abdullahi Alhassan, Department of Physical and Health Education, \\ Federal College of Education, Kano - Nigeria
}

\begin{abstract}
:
Aim: The development of motor skills, fitness knowledge and attitude conducive to a life-time of active lifestyle is cultivated early in life to build 'mens sana in corpore sano'; meaning sound mind in a healthy body. For a successful participation in sporting activities, facilities and equipment must be available for us; hence, this study assessed the availability and utilization of sporting facilities for fitness and health improvements of staff of Federal College of Education, Kano, Nigeria.

Methods: The survey research design which was used because it assessed prevalent conditions without manipulating variables. The population consisted the entire academic and non-academic [N=1580; $M=985$, $F=595]$ staff of Federal College of Education, Kano. Using the stratified and simple random sampling techniques, ten percent [10\%=158] were sampled from the six [6] Schools of Secondary Education; and for representativeness, thirty percent [30\%; F=47] were females. Consent form containing the explained procedure were completed and returned. The instrument used was a self-constructed questionnaire on 'Assessment of Availability and Utilization of sporting facilities [AAUSF] for fitness and health improvements'; validated and administered to the sampled subjects who utilized the various College sporting facilities. Data collected was analyzed using SPSS V.26 [IBM] using the descriptive [\%] and inferential [Chi square] statistics to test raised hypotheses with significance set at 0.05 .

Results: Results obtained revealed that subjects across all ages regularly used the sporting facilities, but the younger subjects [<35years; 101], and males [94; 59.49\%] are credited with more frequent use hence the significance $[p>0.05]$ and the stated null hypothesis rejected. The results, by work status however, revealed no significant difference [p<0.05] in the use of facilities, hence the null hypothesis was accepted.

Recommendations: This study recommended that the establishment of sports associations within the College; organization of low-organized sporting competitions of intramural nature among all staff members whether active or sedentary and finally, the upgrading of the College sporting facilities and infrastructures to accommodate diverse interest of staff and students will go a long way to improving staff participation across the divide of age, gender and status and increase level of socialization for sustained fitness and health improvements.
\end{abstract}

Keywords: Facilities, Fitness, Infrastructures, Low-Organized, Sedentary

Appreciation: Author appreciates the Tertiary Education Trust Fund [TETFUND] for the financial support in carrying out the research work

\section{INTRODUCTION}

Sport is an indispensable part of education; and at all levels of studies, it is a part of the life experiences for both students and staff for most of the last century [Bucher, 2001]. In the early years, sport was purely recreational or associated with training physical education teachers and the uniformed personnel [Olajide, 2004], however, in academic use, it is the only subject area devoted in the study of human movement, the acquisition of motor skills, and the promotion of fitness [Adeyanju, 2009]. Thus, sporting activities are concerned with the total development of the individual; encompassing developments in the psychomotor, cognitive and affective domains. The development of motor skills, fitness, knowledge, and attitude conducive to a life-time of participation is a commonly acknowledged goal of any physical activity program [Onyejiemezie, 2002]. 
Sporting activities that are organized and administered in the school system in Nigeria is not limited to students' participation alone [Olajide, 2004]. The aim of such activities at this level is to build in the participant's 'mens sana in corpore sano'; meaning, sound mind in a healthy body [Bucher, 2001]. Specifically, this is to meet the physical, emotional, social, physiological and intellectual needs of both learners and their supervisors; thus, starting the young ones early in life to health and fitness; and to the adults, maintenance of high health and fitness status for life. This view is equally buttressed by Omoruan (1996), when he asserts that institutional sports is aimed at meeting health needs, and the promotion of optimum development of students and staff. In addition, participating in sports at this level is for fun, play and recreation, hence amateurish in its entirety, the objectives of which include social interaction, physical fitness, skill acquisition and health maintenance with a possible carry over value for the future.

For a successful participation in sporting activities, the needed equipment must be available and capable of being stored for safety and prevention from damage [Omoruan, 1996]; because equipment is a critical component of a quality physical education and sporting program, not only because tools needed to be in sufficient number so that there is free will participation, but also because equipment differentiate quality of participation, increase in the levels of free will participation and in building an individual's self-confidence and self-efficiency [Igbanugo, 1983; Fishbein, 2000]. The same goes for sports facilities which include surfaces, natural or artificial on which sporting and other fitness-related activities done. They may be located indoors or outdoors, the most important thing is their effective utilization [Adeyanju, 2009]. Sports facilities can be utilised in two major ways that allow participants and other fitness enthusiasts to participate and stay healthy while doing so [Thomas, 2005]. They can also play vital roles in preventing injury or treat injuries. For instance, if a fitness enthusiast sprains an ankle, the training room, an important facility, can support the performance of physical therapy on the injured ankle after which icing treatment can take place [McChung, 2016]. This is the role of an essential sports facility during training.

Bucher [2001] describes sports facilities in terms of material infrastructures such as track and field ground and pitches, football field, the swimming pool, all sports and game pitches and courts and the gymnasium; which are required for sports experience. Facilities, Bucher, [2001] emphasize further, play a major role in the organization and administration of sports because they not only facilitate the ease with which a task of training is done; they arouse the interest of the participant, irrespective of their age or gender. Bragaru, et al. (2013) then concluded that facilities serve as morale boosters in performing sport among fitness enthusiasts, thus enhancing to a great extent their happiness and fulfillment of their goals. A successful utilization of sports equipment and facility has a role to play in advancing individual performance status and consequently, health and fitness promotion [Rintaugu, 2011; Azjen, 2014].

Gender and body composition constitute no barrier to participating in physical exercises, even when work schedule is a hindrance. However, when a person is not physically fit due to sedentary lifestyle arising from work schedule, there is that tendency to continue with that lifestyle of inactivity [Walid, et al.; 2014; Venkateswarlu, 2015]. It is, therefore, pertinent that no matter the skill level of the participant, the best way out of the negative effects of inactivity is to create time and begin an activity [Genin, et al.; 2018]. This is borne out of the fact that inactivity begets many degenerative afflictions that will eventually hinder health and fitness status in the chosen vocation [Venkateswarlu, 2015].

Academic and non-academic staff of Federal College of Education, Kano, usually engages in teaching, research and administrative duties; conduct and mark examination in different Nigeria Certificate in Education programmes, thus burdening their supposed free hours with official duties. In spite of these official engagements, it is expected that they create time for sports participation [Lemieux and Godin, 2009]; because it helps in moulding behavioral patterns, which are usually carried over to the society. There is no gainsaying that virtues like high sense of judgment, development of a sound mind and capacity to concentrate are gains imbibed through sports participation with a concomitant improved quality of life [Bruks and Fereira, 2014]. To achieve these goals there must be adequate provision of facilities and equipment; and they must be utilized for the purposes for which they are provided [Olajide, 2004]. It is against this background that this study intends to assess the availability and utilization of sporting facilities for fitness and health improvement of staff of Federal College in Education, Kano - Nigeria. 
Availability and Utilization of Sporting Facilities for Fitness and Health Improvement of Staff of Federal College of Education, Kano, Nigeria.

\section{METHODS AND MATERIALS}

Research Design: This study assessed availability and utilization of sporting facilities for fitness and health improvements of staff of Federal College of Education, Kano. To achieve the stated objectives, the survey research design was used because it assessed conditions that are prevalent and variables are not manipulated; rather it assisted in obtaining quantitative description of the general characteristics of the group being studied.

Population and sample of the Study: The population consisted of the entire academic and nonacademic, male and female [N=1580; M=985, F=595] staff of Federal College of Education, Kano Using the stratified and simple random sampling techniques, ten percent $[10 \%=158]$ were sampled from the six [6] Schools of Secondary Education [Teaching staff $=66$; Non teaching $=92]$ and to further ensure representativeness, thirty percent [30\%] were females [F=47] [Patel, Doku and Tennakoon, 2003] and the rest, males [M=111]. This sample size is adequate and representative [McChung, 2016]. Consent form, in which all the instructions and procedure of the research work are explained for easy understanding was completed by the subjects.

Instrument for Data Collection: The instrument used for data collection was self-constructed questionnaire on 'Availability and Utilization of sporting facilities [AUSF] for fitness and health improvements was validated and administered to the sampled subjects who were observed for eight [8] weeks to assess their utilization of the various College sporting facilities. The questionnaire was divided into three sections A: [demographic information], B: [opinion on sport facility available], C: [self-assessment on utilization] and D: [perceived benefits in sport facility utilization].

Validity of the Instrument: Three [3] sports management professionals were involved in the validation of the instrument. Their observations were effected before administration of instrument

Reliability of the instrument: Reliability coefficient of 0.77 was obtained after applying the testretest reliability technique on the validated instrument.

Data Analysis: Data collected was analyzed using SPSS V.26 [IBM]. The descriptive statistics of frequency $[\mathrm{F}]$ and percentages $[\%]$ was used to analyse demographic information and inferential [Chi square] statistics was used to test raised hypotheses with significance level set at 0.05 .

\section{RESULTS AND DISCUSSION}

This study assessed the availability and utilization of sporting facilities that could contribute to fitness and health promotion of staff of Federal College of Education, Kano - Nigeria.

\subsection{Results}

Results of demographic information of subjects sampled for the study are presented in tables below.

Table1. Distribution of subjects by demographic information and work status

\begin{tabular}{|l|l|l|}
\hline Variable & Options & Frequency [\%] \\
\hline Age & $<25 y r s$ & $62[39.24]$ \\
& $26-35$ yrs & $47[29.75]$ \\
& $36-45 \mathrm{yrs}$ & $28[17.72]$ \\
& $\geq 46 y r s$ & $21[13.92]$ \\
\hline Total & & $158[100]$ \\
\hline Gender & Male & $111[70.25]$ \\
& Female & $47[29.75]$ \\
\hline Total & & $158[100]$ \\
\hline Work Status & Teaching & $66[41.77]$ \\
& Non teaching & $92[58.23]$ \\
\hline Total & & $158[100]$ \\
\hline
\end{tabular}

A cursory look at Table 1 revealed that participation in the study declined by age with the highest 62 [39.24\%] being <25 years and the lowest $21[13.92 \%$ ] being above $\geq 46 y e a r s$ of age; while 111 male subjects representing $70.25 \%$ and 47 females [29.75\%] took part in the study. However, there were more non teaching 92 [58.23\%] than teaching 66 [41.77\%] staff that took part in the study. 
Availability and Utilization of Sporting Facilities for Fitness and Health Improvement of Staff of Federal College of Education, Kano, Nigeria.

Table2. Perception of respondents on adequacy of available sporting facilities on checklist

\begin{tabular}{|l|l|l|l|}
\hline Available Games facilities checklist & Adequate [\%] & Not Adequate [\%] & Total \% \\
\hline $\begin{array}{l}\text { Ball games [05]: Soccer Volleyball, } \\
\text { Handball, Basketball, Hockey }\end{array}$ & $82[51.9]$ & $76[48.1]$ & $158[100]$ \\
\hline 400m Athletics Track [01] & $72[45.57]$ & $86[54.43]$ & $158[100]$ \\
\hline $\begin{array}{l}\text { Racket games [03]: Tennis, T/Tennis, } \\
\text { Badminton }\end{array}$ & $33[20.89]$ & $125[79.11]$ & $158[100]$ \\
\hline Indoor sports [01] & $146[92.41]$ & $12[7.59]$ & $158[100]$ \\
\hline Gymnasium [01] - Fitness & $153[96.84]$ & $05[3.16]$ & $158[100]$ \\
\hline
\end{tabular}

Careful observation of Table 2 revealed the perception of subjects on adequacy or otherwise of sporting facilities available in the college. Results showed that perception on adequacy of racket games facilities was lowest 33 [20.89\%] and highest with gymnasium 153 [96.84\%] and indoor sports hall 146 [92.41\%]; whereas the participants had almost equal perception on adequacy of ball games facilities 82 [51.9\%] and inadequacy of $400 \mathrm{~m}$ athletics track 86 [54.43\%]. Their perception is probably based on interest of sports they take part in.

Table3. Cross tabulation and Chi square analysis on regular use of facilities by age

\begin{tabular}{|c|c|c|c|c|c|c|}
\hline \multirow{2}{*}{$\begin{array}{l}\text { VARIABLE } \\
\text { Facilities use }\end{array}$} & & \multicolumn{5}{|c|}{ Age [years] } \\
\hline & & $<25 y r s$ & $26-35 y r s$ & $36-45 y r s$ & $\geq 46 \mathrm{yrs}$ & Total \\
\hline $\begin{array}{ll}\text { Regular use } & \\
\qquad & \mathrm{O}= \\
\text { within age } & \end{array}$ & $\%$ & $\begin{array}{l}59 \\
59.3 \\
37.3 \% \\
\end{array}$ & $\begin{array}{l}42 \\
41.3 \\
26.6 \%\end{array}$ & $\begin{array}{l}18 \\
19.3 \\
11.4 \%\end{array}$ & $\begin{array}{l}05 \\
6.4 \\
3.16 \% \\
\end{array}$ & $\begin{array}{l}124 \\
126.3 \\
78.5 \% \\
\end{array}$ \\
\hline $\begin{array}{l}\text { Not regular: } \mathrm{O}= \\
\mathrm{E}= \\
\% \text { within age }\end{array}$ & & $\begin{array}{l}03 \\
3.09 \\
1.9 \% \\
\end{array}$ & $\begin{array}{l}05 \\
6.4 \\
3.16 \% \\
\end{array}$ & $\begin{array}{l}10 \\
9.58 \\
6.3 \%\end{array}$ & $\begin{array}{l}16 \\
12.63 \\
10.1 \% \\
\end{array}$ & $\begin{array}{l}34 \\
31.7 \\
21.5 \%\end{array}$ \\
\hline 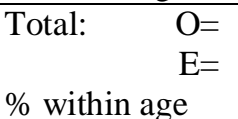 & & $\begin{array}{l}62 \\
62.39 \\
39.2 \%\end{array}$ & $\begin{array}{l}47 \\
47.7 \\
29.8 \%\end{array}$ & $\begin{array}{l}28 \\
28.88 \\
17.7 \%\end{array}$ & $\begin{array}{l}21 \\
19.03 \\
13.3 \%\end{array}$ & $\begin{array}{l}158 \\
158.0 \\
100 \%\end{array}$ \\
\hline
\end{tabular}

$X_{[3]}^{2}=7.815>0.05 \quad *$ Significant

Examination of Table 3 revealed the frequency of sporting facilities use for fitness and health promotions. Results showed variable response based on level of participation. While all subjects across all ages [124; 78.5\%] used the sporting facilities regularly, the young subjects [ $<25 \mathrm{yrs}, 59 ; 26$ $35 y r s, 42]$ are credited with more frequent use. Few of the older subjects [ $\geq 36 y r s: 26 ; 16.4 \%]$ are more implicated for less frequent use of facilities.

However, when these results are subjected to Chi square statistic, results showed that there is significant difference between the different age groups $\left[X^{2}{ }_{[3]}=7.815>0.05 \quad\right]$ in regular use [78.5\%] and non-regular use [21.5\%] of sporting facilities for fitness and health. Thus, the null hypothesis of no significant difference in the use of sporting facilities was not accepted.

Table4. Cross tabulation and Chi square analysis on use of facilities by gender

\begin{tabular}{|l|l|l|l|}
\hline VARIABLE & Gender & Female & Total \\
\cline { 2 - 4 } Facilities use & Male & 28 & 122 \\
Regular use: $\mathrm{O}=$ & 94 & 28.0 & 122.0 \\
$\mathrm{E}=$ & 94.0 & $17.72 \%$ & $77.21 \%$ \\
\% within gender & $59.49 \%$ & 19 & 36 \\
Not regular: $\mathrm{O}=$ & 17 & 19.0 & 36.0 \\
$\mathrm{E}=$ & 17.0 & $12.02 \%$ & $22.79 \%$ \\
\% within gender & $10.77 \%$ & 47 & 158 \\
\hline Total: $\mathrm{O}=$ & 111 & 47.0 & 158.0 \\
$\mathrm{E}=$ & 111.0 & $29.74 \%$ & $100 \%$ \\
\hline within gender & $70.26 \%$ & & \\
\hline
\end{tabular}

$X^{2}{ }_{[1]}=3.841>0.05$

*Significant

Use of sporting facilities by gender, as presented in Table 4 showed that male subjects that regularly use sporting facilities [94;59.49\%] is higher than females [28;17.72\%]; while across gender $77.21 \%$ regularly use sporting facilities while $22.79 \%$ do not. Chi square statistic results however revealed 
Availability and Utilization of Sporting Facilities for Fitness and Health Improvement of Staff of Federal College of Education, Kano, Nigeria.

that there is significant difference by gender $\left[X^{2}{ }_{[3]}=7.815>0.05\right]$ in their regular use of sporting facilities for fitness and health. Thus, the null hypothesis of no significant difference in the use of sporting facilities was not accepted.

Table5. Cross tabulation and Chi square analysis on use of facilities by work status

\begin{tabular}{|c|c|c|c|}
\hline \multirow{2}{*}{$\begin{array}{l}\text { VARIABLE } \\
\text { Facilities use }\end{array}$} & \multicolumn{3}{|c|}{ Work status } \\
\hline & Teaching & N/teaching & Total \\
\hline Regular use: $\mathrm{O}=$ & 45 & 68 & 113 \\
\hline $\mathrm{E}=$ & 46.1 & 57.5 & 103.6 \\
\hline$\%$ within gender & $28.48 \%$ & $36.71 \%$ & $65.19 \%$ \\
\hline Not regular: $\mathrm{O}=$ & 21 & 24 & 45 \\
\hline $\mathrm{E}=$ & 33.9 & 20.5 & 54.4 \\
\hline$\%$ within gender & $22.15 \%$ & $12.66 \%$ & $34.81 \%$ \\
\hline Total: $\quad \mathrm{O}=$ & 66 & 92 & 158 \\
\hline $\mathrm{E}=$ & 80.0 & 78.0 & 158.0 \\
\hline$\%$ within gender & $50.63 \%$ & $49.37 \%$ & $100 \%$ \\
\hline
\end{tabular}

$X_{[1]}^{2}=3.841<0.05 \quad$ Not Significant

A careful observation of Table 5 revealed the role subjects' work status play in their regular use and non-use of sporting facilities in the area of study. Results showed that 45 and 68 teaching and non teaching staff respectively representing $65.19 \%$ regularly use sporting facilities. These difference, when subjected to Chi square statistics was not significant $\left[X_{[1]}^{2}=3.841<0.05\right]$, thus the stated null hypothesis was not rejected.

Table6. Cross tabulation and Chi square analysis on use of facilities on checklist by age, gender and work status

\begin{tabular}{|c|c|c|c|c|c|c|}
\hline \multirow{2}{*}{$\begin{array}{c}\text { Variable } \\
\text { Facilities utilization }\end{array}$} & \multicolumn{6}{|c|}{ Checklist of available facilities and their utilization } \\
\hline & $\begin{array}{l}\text { Ball } \\
\text { games }\end{array}$ & $\begin{array}{l}\text { Athletics } \\
\text { track }\end{array}$ & $\begin{array}{l}\text { Racket } \\
\text { games }\end{array}$ & $\begin{array}{l}\text { Indoor } \\
\text { sport }\end{array}$ & $\begin{array}{l}\text { Gymna- } \\
\text { sium }\end{array}$ & Total \\
\hline Age [yrs] a: <25yrs & 17 & 17 & 13 & 03 & 12 & $62[39.24]$ \\
\hline b:26 - 35yrs & 20 & 10 & 08 & 01 & 08 & $47[29.75]$ \\
\hline c: $36-45 y r s$ & 07 & 03 & 06 & 02 & 10 & $28[17.72]$ \\
\hline $\mathrm{d}: \geq 46 \mathrm{yrs}$ & 00 & 01 & 04 & 04 & 12 & $21[13.92]$ \\
\hline TOTAL & 44 & 31 & 31 & 10 & 42 & $158[100]$ \\
\hline$\%$ use within facility & $27.85 \%$ & $19.62 \%$ & $19.62 \%$ & $6.33 \%$ & $26.58 \%$ & $100 \%$ \\
\hline Gender: $\quad$ a. Male & 37 & 12 & 26 & 11 & 25 & 111 [70.25] \\
\hline b. Female & 02 & 05 & 04 & 14 & 22 & $47[29.75]$ \\
\hline TOTAL & 39 & 17 & 30 & 25 & 47 & $158[100]$ \\
\hline$\%$ use within facility & $24.68 \%$ & $10.76 \%$ & $18.99 \%$ & 15.82 & $29.75 \%$ & $100 \%$ \\
\hline Work status: a:Teaching & 24 & 08 & 18 & 05 & 11 & 66 [41.77] \\
\hline b. Non teaching & 33 & 20 & 19 & 09 & 11 & $92[58.23]$ \\
\hline TOTAL & 57 & 28 & 37 & 14 & 22 & $158[100]$ \\
\hline$\%$ use within facility & $36.08 \%$ & $17.72 \%$ & $23.42 \%$ & $8.86 \%$ & $13.92 \%$ & $100 \%$ \\
\hline
\end{tabular}

A careful examination of Table 6 showed that age and gender [p>0.05] but not work status have significant effects on the subjects' interest in assessing the various games on the facilities presented on the checklist of this study. While the younger the subjects' interest tilted to ball games, athletics track and racket games, the older subjects' preference was for indoor sports and gym workouts. Thus, the null hypothesis of no significant difference was not accepted by age and gender, but was accepted by work status $[\mathrm{p}<0.05]$.

\section{DISCUSSION}

Physical activity is prescribed to reduce adiposity and overweight, and consequently improve on fitness and health status of exercise adherents [Adeyanju, 2009]; but the benefits can only accrue for those who devotedly utilize available sporting facilities for workouts.

Data on age showed that subjects were not homogenous as there was wide variations from the youngest [<25yrs] to the oldest [ $\geq 45 \mathrm{yrs}$ ] groups thereby giving an insight on ability to engage in certain types of physical exertion [Mohammed, et al.; 2018]. The role of gender and work status on the use of sporting facilities has been discussed [Krieger, et al.; 1997; Stockie, 2009; Walid, et al.; 2014]; however, 
individual perception which is based on availability determines the sporting facilities to be utilized. Results of this study on perception revealed adequacy of facilities for ball games [51.9\%], indoor sports [92.41\%] and gymnasium [96.84\%]; but not so for athletics track [45.57\%] and racket games [20.89\%]. This result supports the assertion of several authorities [Shuaibu, 2009; Bragaru, et al.; 2013] reported that it is difficult to have adequate facilities for effective training in our institutions.

It has been suggested that youths are more mobile and adventurous, and this is reflected in their regular use of sporting facilities as reported in this study [ $>25 \mathrm{yrs} ; 37.3 \%$ and $26-35 \mathrm{yrs} ; 26.6 \%$ ] compared to the older persons [36-45yrs; $11.4 \%$ and $\geq 46 y r s ; 3.16 \%$ ]. Statistical analysis was significant [p $>0.05]$ and the null hypothesis was not accepted on the basis that the younger the better work output [Adeyanju, 2009; Shuaibu, 2009]. There is further suggestion that cultural and societal influences are hindrances on gender participation in sports [Adeyanju, 2009] as reported in this study that male subjects use sports facilities more regularly [59.49\%] as against females [17.72\%]. The null hypothesis was however, not accepted $[p>0.05]$ on the basis that gender has significant effects on sports participation.

There are different categories of staff in every establishment and this area of study is not an exemption. Although, data on status of a staff and effects on sports performance is scanty, this study has revealed that $36.71 \%$ of non teaching staff engages more in sporting activities than their teaching counterparts [28.48\%]. This is probably due to work schedule and related pressures [Landsbergis, et al.; 2003; Genin, et al.; 2018] of teaching, counseling and monitoring assignments of subjects. This assertion supports that found in military set up [Shuaibu, 2009] in which the commissioned officers staff enjoy less physical exertion than their junior counterparts, Government offices like MDAs [Shuaibu, 2009; Mohammed, et al.; 2018] where directors are more sedentary than the junior staff and in super stores [Stockie, 2009] where the managers are not as active as sales boys and girls. This study, however, presented no significant difference in the use of sporting facilities in the area of study despite the percentage margin between teaching and non teaching staff. This result supports Jenum, et al. [2009] and Christopher, et al.; [2020] assertion that as an officer rises in official and economic status, sedentary lifestyle becomes the bane.

The preponderance of sports facilities [checklist] utilization by age, gender and work status revealed that these variables play major roles. For instance, while $>25 \mathrm{yrs}$ and 26-35yrs utilized ball games, athletics track, racket games and gymnasium facilities that require mobility and power exertion; the older subjects [36-45yrs and $\geq 46 y$ yrs] concentrated more on the use of gymnasium where fitness workouts are carried out at individual pace [Table 6]. When gender was focused upon, the males utilized all the facilities [70.25\%] as against the female groups' concentration on indoor sports and gymnasium facilities with social and cultural hindrances as the bane. However, ball games, athletics track, racket games and the gymnasium facilities are more patronized by work status with the nonteaching staff having higher use than their teaching staff counterparts.

\section{CONCLUSION AND RECOMMENDATION}

The regular use of sporting facilities has numerous fitness and health improvements which include, but not limited to reduced blood pressure, lower body weight and blood sugar levels, healthy Cadiovascular $[\mathrm{CV}]$ system, Cardio respiratory $[\mathrm{CR}]$ and muscular endurance and improved breathing rates to every member of staff in the College that uses them. The gains can be experienced by all without restrictions, even though natural phenomenon like age; and artificial restrictions like sociocultural [gender] factors cannot be completely eliminated. Considering that no institution can provide all the sporting facilities required by everyone in the system as interest base differs, staff needs to utilize the limited facilities available for their fitness and health benefits. In view of the foregoing, the following recommendations are put forward:

$\checkmark$ The College sporting facilities and infrastructures need to be expanded to accommodate diverse interest of staff and students for sustained fitness and health improvements

$\checkmark$ There should be low-organized sporting competitions of intramural nature among staff to encourage staff members that are prone to sedentary lifestyles.

$\checkmark$ Staff sports travels should be encouraged as change of environment encourages better outlook to work output.

$\checkmark$ The establishment of sports associations within the College as a way of removing the barriers to participation among different age groups, gender and status. It improves the level of socialization 


\section{REFERENCES}

[1] Adeyanju, E. S. [2002]. Comparative effects of continuous and interval training on body composition and Lipiproteins profiles of adolescents in Nigeria. Unpublished PhD Dissertation, ABU Zaria.

[2] Adeyanju, E. S. [2009]. Effects of Interval Training on Lipid profiles of adolescent Nigerian boys and girls. Medicina Dello Sport; Revista Della Federazione Medico Sportiva-Italy Vol. 62[1]: Pgs 33-44.

[3] Azjen, I. [2014]. The theory of planned use of leisure hours. Org. Behav. Hum. Decision proc., Vol. 50. pgs $179-211$

[4] Bragaru, M., Van, W.,Gertzen, J. B. and Dijkstra, P.U. [2013]. Barriers and facilitators of sports participation. Plos One 8[3]: Retrieved from www.plosone.org

[5] Bruks, J. Onema, A. and Fereira, I. [2014]. Trackimg of Leisure time physical activity in adulthood through old age. Int. J. Behav. and Nutr. Vol. 5, No. 69; pg 56

[6] Christopher, E. J., DeWolfe, M. C., Watt, P. R., and Sherry, H. S. [2020]. Gender difference in Physical activity as explained by anxiety sensitivity. Journ. Am. Coll. Health, 68:3.

[7] Fishbein, M. [2000]. The role of facilities in sports participation among adults. Vol. 12, pgs 278-278.

[8] Genin, P. M, Dessenne, P., Finnard, J. et al., [2018]. Effect of work-related sedentary time on overall health. Journal of Frontiers in Public Health. 6[2]: Pgs 12-18

[9] Igbanugo, V. C. [1983]. Importance of facilities and equipment in sport development. Journal of Sports Mgt and Educ. Research. Vol. 2; No. 3, pgs 34-39

[10] Jenum, A. K., Lorentzen, C. A., and Ommundsen, Y, [2009]. Targeting physical activity in a low socioeconomic status population. Br. J. Sport Med. Pub. Health. Vol. 6[2]: 5-12

[11] Krieger, N., Williams, D. R., and Moss, N. E. [1997]. Measuring social class in US public health: Concepts and guidelines. Annual Rev. Pub. health; Vol 3, No 2; 26-30

[12] Landsbergis, P. A., Schnall, P., Pickering, T. G., et al., [2003]. Lower socioeconomic status and job strain among men. Scand. J. Work Environ. Health. 5[3]: Pg 9-14

[13] Lemieux, M. and Godin [2009]. Individual and group participation in active pursuits. Physical Activity. Vol. 6; pg. 22

[14] McChung, C. [2016]. How to obtain representative sample from a population size. Quora.com

[15] Mohammed, A. E., Usha, T., Abubakar, H. M., and Dhirendra, T. [2018]. Effect of Socio-economic status on sports barrier perception. UAE JASPE, Vol. 1, No. 4; Pgs 6 - 9

[16] Olajide, O. A. [2004]. Sports facilities: A problem to schools sports in Nigeria. Int. J. Emotional and Psych. Sports Ethics. Vol. 6; pgs 19-23

[17] Omoruan, J. C. [1996]. The need for equipment and facilities for sports and recreation centers. Benin: Odenigbu Printing Press

[18] Onyejiemezie, D. S. [2002]. Impact of selected sports management indices on adult fitness programmes in Nigerria. Unpublished PhD Dissertation, University of Ibadan-Nigeria

[19] Patel, M., Doku, V. and Tennakoon, L. [2003]. Challenges in recruitment of experimental research participants. Assessed on 23 June, 2011

[20] Rintaugu, E. G. [2011]. Availability and adequacy of sports facility and equipment in selected schools in Kenya. https://ir-library.ku.ac

[21] Shuaibu, A. A. [2009]. Availability of sporting facilities and sports participation of personnel in military formations in Nigerian Army. Kano: Unpublished M.Sc Sport Mgt. dissertation, BUK

[22] Stockie, M. L. [2009]. Relationship between socioeconomic status and physical activity levels. Theses and Dissertation [Comprehensive]. Retrieved from https://scholars.wlu.

[23] Thomas, K. B. [2005]. Consumables and their effective use in sports and fitness promotions. Kaduna: Hurricane Publishers

[24] Venkateswarlu, K. [2015]. Exercise Prescription for disease prevention, adult health and fitness promotions. Zaria: ABU Press

[25] Walid, E. A., Khalid, K., Diane, C. and Christiane, S. [2014]. Physical activity and gender differences among students in Libya. Cent Eur J. Pub Health 22[2]: pgs 26-33

Citation: Shuaibu Abdullahi Alhassan, et.al. " Availability and Utilization of Sporting Facilities for Fitness and Health Improvement of Staff of Federal College of Education, Kano, Nigeria." International Journal of Sports and Physical Education (IJSPE), vol 6, no. 3, 2020, pp. 01-07. doi: https://doi.org/10.20431/24546380.0603001 .

Copyright: () 2020 Authors. This is an open-access article distributed under the terms of the Creative Commons Attribution License, which permits unrestricted use, distribution, and reproduction in any medium, provided the original author and source are credited. 